\title{
The relationship between sedentary behaviour and physical literacy in Canadian children: a cross-sectional analysis from the RBC-CAPL Learn to Play study
}

Travis J. Saunders ${ }^{1 *}$, Dany J. MacDonald ${ }^{1}$, Jennifer L. Copeland ${ }^{2}$, Patricia E. Longmuir ${ }^{3}$, Joel D. Barnes ${ }^{3}$, Kevin Belanger ${ }^{3}$, Brenda Bruner ${ }^{4}$, Melanie J. Gregg ${ }^{5}$, Nathan Hall ${ }^{5}$, Angela M. Kolen ${ }^{6}$, Barbi Law ${ }^{4}$, Luc J. Martin? Dwayne Sheehan ${ }^{8}$, Michelle R. Stone ${ }^{9}$, Sarah J. Woodruff ${ }^{10}$ and Mark S. Tremblay ${ }^{3}$

\begin{abstract}
Background: Physical literacy is the foundation of a physically active lifestyle. Sedentary behaviour displays deleterious associations with important health indicators in children. However, the association between sedentary behaviour and physical literacy is unknown. The purpose of this study was to identify the aspects of physical literacy that are associated with key modes of sedentary behaviour among Canadian children participating in the RBC-CAPL Learn to Play study.

Methods: A total of 8,307 children aged 8.0-12.9 years were included in the present analysis. Physical literacy was assessed using the Canadian Assessment of Physical Literacy, which measures four domains (Physical Competence, Daily Behaviour, Motivation and Confidence, Knowledge and Understanding). Screen-based sedentary behaviours (TV viewing, computer and video game use), non-screen sedentary behaviours (reading, doing homework, sitting and talking to friends, drawing, etc.) and total sedentary behaviour were assessed via self-report questionnaire. Linear regression models were used to determine significant $(p<0.05)$ correlates of each mode of sedentary behaviour.

Results: In comparison to girls, boys reported more screen time (2.7 \pm 2.0 vs $2.2 \pm 1.8$ hours/day, Cohen's $d=0.29$ ), and total sedentary behaviour ( $4.3 \pm 2.6$ vs $3.9 \pm 2.4$ hours/day, Cohen's $d=0.19)$, but lower non-screen-based sedentary behaviour (1.6 \pm 1.3 vs $1.7 \pm 1.3$ hours/day, Cohen's $d=0.08$ ) (all $p<0.05$ ). Physical Competence (standardized $\beta$ 's: -0.100 to -0.036 , all $p<0.05$ ) and Motivation and Confidence (standardized $\beta^{\prime} s$ : -0.274 to -0.083 , all $p<0.05$ ) were negatively associated with all modes of sedentary behaviour in fully adjusted models. Knowledge and Understanding was negatively associated with screen-based modes of sedentary behaviour (standardized $\beta$ 's: -0.039 to -0.032 , all $p<0.05$ ), and positively associated with non-screen sedentary behaviour (standardized $\beta$ : 0.098, $p<0.05$ ). Progressive Aerobic Cardiovascular Endurance Run score and log-transformed plank score were negatively associated with all screen-based modes of sedentary behaviour, while the Canadian Agility and Movement Skill Assessment score was negatively associated with all modes of sedentary behaviour other than TV viewing (all $p<0.05$ ).

Conclusions: These results highlight differences in the ways that screen and non-screen sedentary behaviours relate to physical literacy. Public health interventions should continue to target screen-based sedentary behaviours, given their potentially harmful associations with important aspects of physical literacy.
\end{abstract}

Keywords: Physical literacy, Sedentary behaviour, Screen time, TV, Computer, Video game, Reading, Physical activity

\footnotetext{
* Correspondence: trsaunders@upei.ca

'Department of Applied Human Sciences, University of Prince Edward Island,

550 University Avenue, Charlottetown, PE C1A 4P3, Canada

Full list of author information is available at the end of the article
}

(c) The Author(s). 2018 Open Access This article is distributed under the terms of the Creative Commons Attribution 4.0 International License (http://creativecommons.org/licenses/by/4.0/), which permits unrestricted use, distribution, and reproduction in any medium, provided you give appropriate credit to the original author(s) and the source, provide a link to the Creative Commons license, and indicate if changes were made. The Creative Commons Public Domain Dedication waiver (http://creativecommons.org/publicdomain/zero/1.0/) applies to the data made available in this article, unless otherwise stated. 


\section{Background}

Sedentary behaviour (SB) refers to any behaviour done with a low energy expenditure $(\leq 1.5$ METs [metabolic equivalents]) while sitting, reclining, or lying down [1]. SBs are increasingly prevalent among children in developed nations [2, 3], and are deleteriously associated with numerous physical and psycho-social health indicators in pediatric populations [4-6]. A recent systematic review by Carson et al. [4] concluded that children who accumulate large amounts of SB, and especially screen-based SBs (e.g., television, computer and video games), tended to have unfavourable measures of body composition, cardiometabolic risk, physical fitness, behavioural conduct/prosocial behaviour and self-esteem. It has also been noted that the associations between SBs and health differ based on the modality of SB; screen-based SBs tend to be adversely associated with health indicators, while non-screen-based SBs (e.g., reading) typically display a neutral or even beneficial association with health $[2,4]$.

Physical literacy (PL) is defined as "the motivation, confidence, physical competence, knowledge and understanding to value and take responsibility for engagement in physical activities for life" [7]. PL has gained increasing attention in recent years, and has been suggested as the foundation for lifelong healthy active living [8, 9]. Although recent studies have investigated behavioural and socio-demographic correlates of SB [10-15], to date no study has examined the relationship between SB and key components of PL. If there is a relationship between $\mathrm{SB}$ and PL, this could provide support for the role of PL in promoting a healthy active lifestyle.

The Canadian Assessment of Physical Literacy (CAPL) is a valid tool for measuring $\mathrm{PL}$ in children aged 8-12 years, and provides information on four key domains: Daily Behaviour, Physical Competence, Knowledge and Understanding, and Motivation and Confidence [9]. Within the Daily Behaviour domain, the CAPL also measures self-reported TV, computer, and non-screen SB, as well as total SB. In 2014-2016, more than 10,000 children from 11 sites across Canada were included as part of the Royal Bank of Canada-Canadian Assessment of Physical Literacy (RBC-CAPL) Learn to Play study [9]. The purpose of this analysis was to determine if aspects of PL were associated with key modes of SB among participating children.

We hypothesized that all forms of SB would be negatively associated with overall PL, and with individual PL domains. With respect to individual CAPL components, we hypothesized that SB would be positively associated with age and markers of adiposity, and negatively associated with measures of aerobic and musculoskeletal fitness, self-reported physical activity, and the maximum amount of time that participants felt that children in general should spend in front of a screen on a daily basis. Finally, we hypothesized that PL would be more strongly associated with screen-based modes of SB, in comparison to non-screen SB.

\section{Methods}

Participants and study design

Full details of the CAPL, and the RBC-CAPL Learn to Play study, are available via the CAPL website [16] and in previous publications $[9,17]$. Briefly, the CAPL was developed by the Healthy Active Living and Obesity Research Group at the Children's Hospital of Eastern Ontario Research Institute. The CAPL includes eight tests of Physical Competence (outlined below), a 21-item Knowledge and Understanding self-report questionnaire, and the 17-item Children's Self-Perception of Adequacy in and Predilection for Physical Activity (CSAPPA) [18]. Participants were also asked to wear a pedometer for 7 days to measure daily step counts. All tests were administered by trained staff. The validity and reliability of individual CAPL components have been published previously [18-23].

The present analysis was coordinated by the Healthy Active Living and Obesity Research Group at the Children's Hospital of Eastern Ontario Research Institute, and data were collected from 11 sites in 7 Canadian provinces (Table 1). Training of staff at the individual sites took place in May of 2014, and data collection ended in January of 2017. To be included, participants had to be between 8.0 and 12.9 years of age at the time of data collection. Participants were excluded from the study if they had been told by their physician to avoid exercise. There were no other exclusion criteria. Participants were recruited through public and private schools, camps, community recreation centres and after-school programs. Study procedures were approved by research ethics boards at the Children's Hospital of Eastern Ontario Research Institute as well as each individual CAPL site, and by participating school boards and community organizations. Written informed consent was obtained from parents or legal guardians, while assent was obtained from all study participants.

\section{Sedentary behaviour}

Participants were asked to self-report the time spent watching TV, playing video or computer games or using a computer for non-school work, and time spent sitting down doing non-screen-based activities outside of school time (e.g., reading a book, doing homework, sitting and talking to friends, drawing, etc.). Response categories for each question were "I did not spend time" = 0 hours/day, "Less than 1 hour" $=0.5$ hours $/$ day, "1 hour" = 1 hour/day, " 2 hours" = 2 hours/day, " 3 hours" = 3 hours $/$ day, " 4 hours" $=4$ hours $/$ day, 


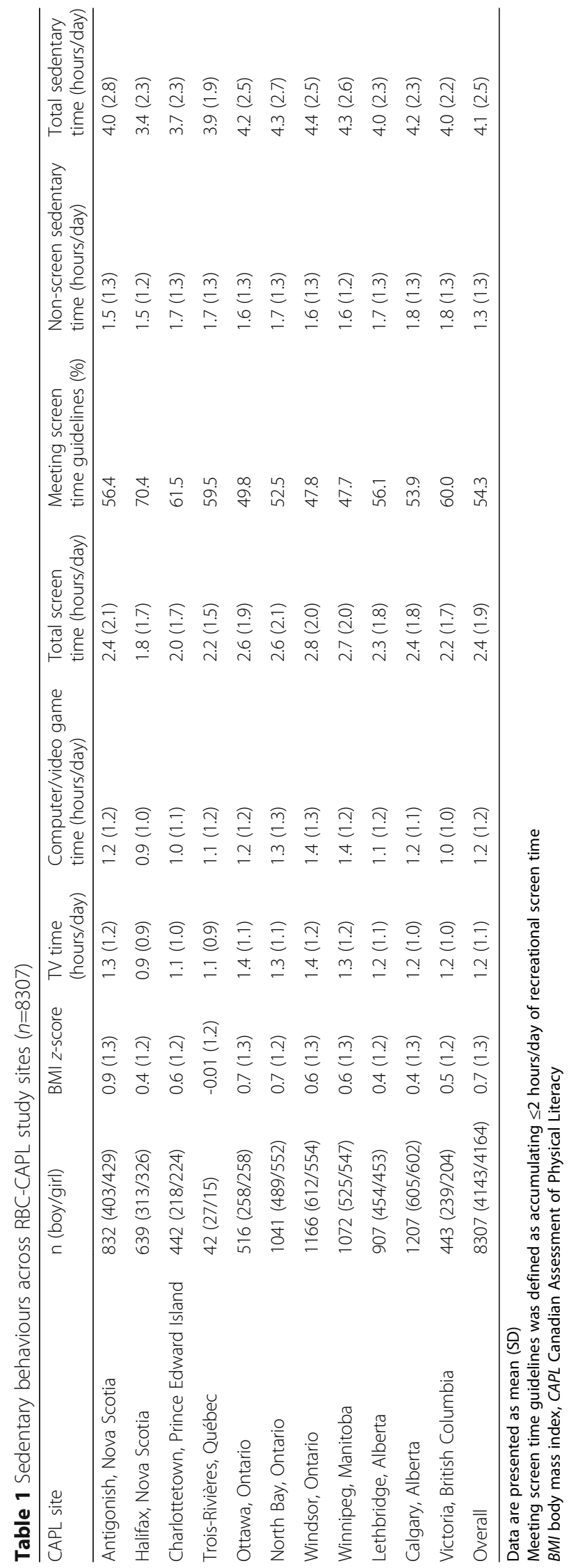


and "5 or more hours" = 5 hours/day. Each question was asked for a typical school day and also for a typical weekend day. A weighted mean of daily time (decimal hours) spent in each mode of SB was calculated using the following equation: [(hours of SB on school days x 5) + (hours of SB on weekends x 2)]/7 $[11,12]$. Average daily TV and computer/video game time were summed to calculate total screen time. TV, computer/video game, and non-screen SBs were summed to calculate total SB. Participants were also asked, "What is the most time that children should look at a screen each day?", with response options of 30 minutes, 1 hour, 2 hours, and 4 hours.

\section{Potential correlates of SB}

\section{Demographic characteristics}

Age and gender were self-reported by participants. CAPL site and season of data collection were recorded by researchers. Seasons were identified as follows: winter $=1$, spring $=2$, summer $=3$, and fall $=4$.

\section{Daily Behaviour}

Using a self-report questionnaire, children were asked, "During the past week (7 days), on how many days were you physically active for a total of at least 60 minutes per day?" and asked to select an option between 0 and 7. Physical activity (PA) was also assessed via SC-StepRx pedometer (StepsCount, Deep River, ON, Canada) [19, 23]. Participants were asked to record the number of steps they took, the time the pedometer was put on in the morning and taken off at night, and the amount of missing hours, in a tracking $\log$ for seven consecutive days. Pedometer data were considered valid if the number of steps fell between 1,000 and 30,000 steps/day, with at least 10 hours of wear-time. For pedometer data to be included, participants were required to have $\geq 3$ valid days, with no minimum requirement for week or weekend days $[24,25]$.

Typically the Daily Behaviour score is calculated out of 32 points, based on the pedometer data, self-reported PA, and SB-related questions [9]. However, for the purposes of this analysis, Daily Behaviour was re-calculated after removing SB-related questions, for a maximum score of 24 points. It was also possible to calculate a Daily Behaviour score using only self-reported PA data if a participant did not have valid pedometer data, which was the case for roughly half of study participants. Because of the large proportion of missing pedometer data, daily steps were not included as an individual variable in other analyses to maximize sample size. Given that the re-calculated Daily Behaviour score was based solely on self-reported PA for many participants in the present analysis, this domain was not included on its own in regression analyses, although it was used to calculate total PL.

\section{Physical Competence}

Physical Competence was assessed by trained study staff using established methods. Motor skills were measured using the Canadian Agility and Movement Skill Assessment (CAMSA) as described by Longmuir et al. [21]. Muscular endurance was assessed using the prone plank, following the protocol validated in this population by Boyer et al. [20]. Handgrip strength, sit-and-reach flexibility, and waist circumference were assessed according to Canadian Society for Exercise Physiology protocols [26]. Aerobic fitness was assessed using the Progressive Aerobic Cardiovascular Endurance Run (PACER) shuttle run [22]. Body mass index (BMI) $z$-scores were calculated using directly measured height and weight and World Health Organization growth curves [27]. Participants also received an overall Physical Competence score based on the above indicators, with a maximum of 32 total points [9].

\section{Knowledge and Understanding}

Knowledge and Understanding were assessed via self-report questionnaire, and a score was calculated out of a possible 18 points [9]. The content of this questionnaire was meant to capture Canadian provincial curricula for physical and health education in grades 4, 5, and 6: awareness of fitness terminology; perceptions of health; use of safety equipment during PA; and basic methods on how to improve fitness levels [9].

\section{Motivation and Confidence}

The Motivation and Confidence domain was assessed via self-report questionnaire. Children were asked to rate their agreement on a scale of 1 (disagree a lot) to 5 (agree a lot) to questions describing PA barriers and benefits (10 and 9 items, respectively) [28]. A benefits-to-barriers ratio was calculated as the perceived benefits minus perceived barriers of PA. Adequacy and predilection subscale scores were used from 16 items taken from the CSAPPA Scale [18]. Finally, PA and skill level compared to others were self-reported with one item each, using a scale from 1 (a lot less active; others are better) to 10 (a lot more active; I'm a lot better).

\section{Overall physical literacy score}

Based on their performance in each of the four individual CAPL domains, participants received an overall PL score out of a maximum of 100 points [9]. For all analyses in the present manuscript, the total PL score was re-calculated after removal of all SB items.

\section{Statistical analyses}

Statistical analyses were conducted using SPSS 25 (IBM SPSS Statistics, New York, NY, USA). All variables were normally distributed except for plank score, which was 
log transformed. Unpaired t-tests and chi-square tests were used to assess differences between boys and girls, and between those with complete data compared to those with missing data. Correlations between each mode of SB were assessed via Pearson $r$. Effect sizes were determined using Cohen's $d$.

Multi-level models were examined with participants nested within sites; however, considering that the variance explained by the sites was $<2.5 \%$ for all modes of $\mathrm{SB}$, linear regression models were used to determine correlates of each mode of SB instead. Potential correlates were initially identified using minimally adjusted models, adjusted only for age and gender. Separate models were run for each potential correlate. Any correlates associated with a mode of SB in the minimally adjusted models $(p<0.10)$ were included in the fully adjusted model for that SB. Fully adjusted models were run twice for each mode of SB: once for CAPL domain scores (Knowledge and Understanding, Physical Competence, and Motivation and Competence), and once for individual CAPL components (BMI $z$-score, PACER score, etc.). Variables that remained significant $(p<0.05)$ in the fully adjusted linear regression model were considered correlates of that mode of SB. Analyses are presented for the total sample, and for boys and girls separately.

BMI $z$-score and waist circumference were highly correlated $(r=0.800 ; p<0.001)$. Therefore, whenever both were significant in initial models for a given mode of SB, the variable accounting for the greater proportion of variance was included in the fully adjusted model to avoid collinearity. In all cases where both were significant, waist circumference was included in the fully adjusted models.

\section{Results}

The full sample included 10,034 participants (5,004 boys, 5,030 girls); 1,727 were missing data for at least one variable of interest, and were excluded from subsequent analyses (Table 2). Although there were several statistically significant differences between those with missing and those with complete data, the effect sizes were small (i.e., $\leq 0.15$ for all differences). In comparison to participants with complete data, those with missing data were younger $(10.5 \pm 1.2$ vs $10.6 \pm 1.2$ years, Cohen's $d=0.08$, $p=0.040$ ); heavier (BMI $z$-score $0.7 \pm 1.3$ vs $0.6 \pm 1.3$, Cohen's $d=0.08, p=0.027$ ); reported lower frequency of PA (4.9 \pm 2.1 vs $5.0 \pm 1.9$ days/week, Cohen's $d=0.06$, $p=0.034)$; and had lower scores for sit and reach (27.6 \pm 8.6 vs $28.2 \pm 8.4 \mathrm{~cm}$, Cohen's $d=0.07, p=0.025$ ), PACER (22.2 \pm 13.2 vs $23.5 \pm 14.2$ laps completed, Cohen's $d=0.09$, $p=0.002)$, CAMSA $(20.2 \pm 4.2$ vs $20.7 \pm 3.8$, Cohen's $d=0.12, p<0.001$ ), and the Motivation and Confidence (12.2 \pm 3.0 vs $12.5 \pm 2.7$, Cohen's $d=0.11, p=0.001)$, Physical
Table 2 Participants with missing data

\begin{tabular}{ll}
\hline Variable & Missing data $(n)$ \\
\hline Age & 105 \\
Sit and reach & 414 \\
Handgrip & 366 \\
PACER & 641 \\
Plank & 428 \\
Waist circumference & 639 \\
BMl z-score & 622 \\
Frequency of PA & 247 \\
TV time & 259 \\
Computer time & 262 \\
Screen time & 264 \\
Non-screen SB & 258 \\
Total SB & 522 \\
Physical Competence & 646 \\
Motivation and Confidence & 409 \\
Knowledge and Understanding & 237 \\
CAPL score & 703 \\
CAMSA & 546
\end{tabular}

Some participants were missing data for multiple variables; 1727 participants were missing data for at least one variable

$B M I$ body mass index, CAMSA Canadian Agility and Movement Skill Assessment CAPL Canadian Assessment of Physical Literacy, PA physical activity, PACER Progressive Aerobic Cardiovascular Endurance Run, $S B$ sedentary behaviour.

Competence $(18.9 \pm 5.1$ vs $19.7 \pm 4.3$, Cohen's $d=0.15$, $p<0.001)$, and Knowledge and Understanding $(11.7 \pm 2.7$ vs $12.1 \pm 2.7$, Cohen's $d=0.15, p<0.001)$ domains of PL.

Descriptive characteristics of study participants are presented in Table 3. Site sample sizes ranged from 42 participants (Trois-Rivières, Québec) to 1,207 participants (Calgary, Alberta). Participants had an average age of 10.6 years, and reported accumulating 2.4 hours/day of screen time, and 4.1 hours/day of total SB. Overall, $54.3 \%$ of participants reported meeting Canadian guidelines for recreational screen time ( $\leq 2$ hours/day), ranging from a low of $47.7 \%$ (Winnipeg, Manitoba) to a high of 70.4\% (Halifax, Nova Scotia).

Differences in sedentary behaviour were small between boys and girls, although boys had higher scores for TV (1.3 \pm 1.2 vs $1.2 \pm 1.0$ hours/day, Cohen's $d=0.10)$, computer/video game use $(1.4 \pm 1.3$ vs $1.0 \pm 1.1$ hours/day, Cohen's $d=0.39)$, total screen time $(2.7 \pm 2.0$ vs $2.2 \pm 1.8$ hours/day, Cohen's $d=0.29)$, and total SB $(4.3 \pm 2.6$ vs $3.9 \pm 2.4$ hours/day, Cohen's $d=0.19$ ), and lower scores for non-screen-based SB $(1.6 \pm 1.3$ vs $1.7 \pm 1.3$ hours/ day, Cohen's $d=0.08$ ) (all $p<0.05$ ) (Figure 1). Girls were more likely than boys to meet Canada's screen time guidelines $(61 \%$ vs $48 \%$, respectively, $p<0.05)$. There was a moderate positive association between 
Table 3 Participant characteristics $(n=8307)$

\begin{tabular}{ll}
\hline Variables & Mean (SD) \\
\hline CAPL domain scores & $62(11.0)$ \\
Total Physical Literacy score (/100) & $12.1(2.7)$ \\
Knowledge and Understanding score (/18) & $12.5(2.7)$ \\
Motivation and Confidence score (/18) & $19.7(4.3)$ \\
Physical Competence score (/32) & \\
Individual CAPL components & $10.6(1.2)$ \\
Age (years) & $0.6(1.3)$ \\
BMI z-score & $67.2(10.7)$ \\
Waist circumference (cm) & $0.9(0.4)$ \\
Most time children should spend in front of a screen \\
(hours/day) & \\
Frequency of PA (days/week) & $5.0(1.9)$ \\
Plank (seconds) & $61.8(43.3)$ \\
Sit and reach (cm) & $28.2(8.4)$ \\
Grip strength (kg) & $33.6(9.4)$ \\
CAMSA score & $20.7(3.8)$ \\
PACER (laps completed) & $23.5(14.2)$ \\
Participants tested in each season (n) & \\
Winter & 1889 \\
Spring & 3122 \\
Summer & 1330 \\
\hline Fall & 1966 \\
\hline Dat &
\end{tabular}

Data presented as mean (SD)

$B M I$ body mass index, CAMSA Canadian Agility and Movement Skill Assessment, CAPL Canadian Assessment of Physical Literacy, PA physical activity, PACER Progressive Aerobic Cardiovascular Endurance Run
TV and computer/video game use $(r=0.40)$, with trivial associations between non-screen $\mathrm{SB}$ and $\mathrm{TV}$ $(r=0.15)$, computer/video game use $(r=0.17)$, or total screen time $(r=0.19)$ (all $p<0.05$; Table 4$)$.

\section{Correlates in minimally adjusted models}

Results from the minimally adjusted models are presented in Tables 5, 6, 7, 8 and 9. Although all PL domains were significantly associated with each mode of SB in the full sample, Motivation and Confidence (standardized $\beta$ 's: -0.300 to -0.078 ) and total PL (standardized $\beta$ 's: -0.272 to -0.038 ) exhibited stronger associations with all modes of SB than Knowledge and Understanding (standardized $\beta$ 's: -0.110 to 0.074 ) or Physical Competence (standardized $\beta$ 's: -0.204 to -0.050 ) (all $p<0.05$ ). Among individual CAPL components, the self-reported maximum amount of time that participants felt children should spend in front of a screen each day was positively associated with all modes of SB (standardized $\beta$ 's: 0.114 to 0.421 , all $p<0.05)$. Gender, frequency of self-reported PA, PACER score, log-transformed plank score, and CAMSA score were all consistently associated with screen-based modes of SB. Season of data collection was the only investigated correlate that did not have a significant association with $\mathrm{TV}$, computer, total screen, and total SB when investigating both genders combined, or when examining boys separately (all $p>0.10$ ).

In contrast to screen-based modes of $\mathrm{SB}$, a smaller number of correlates displayed significant associations with non-screen SB. CAPL site, plank, and sit and reach were not significantly associated with non-screen SB in the group as a whole, or in either gender when examined separately. Non-screen SB was negatively associated with grip strength, and positively associated with BMI $z$-score in boys only. Season of data collection was

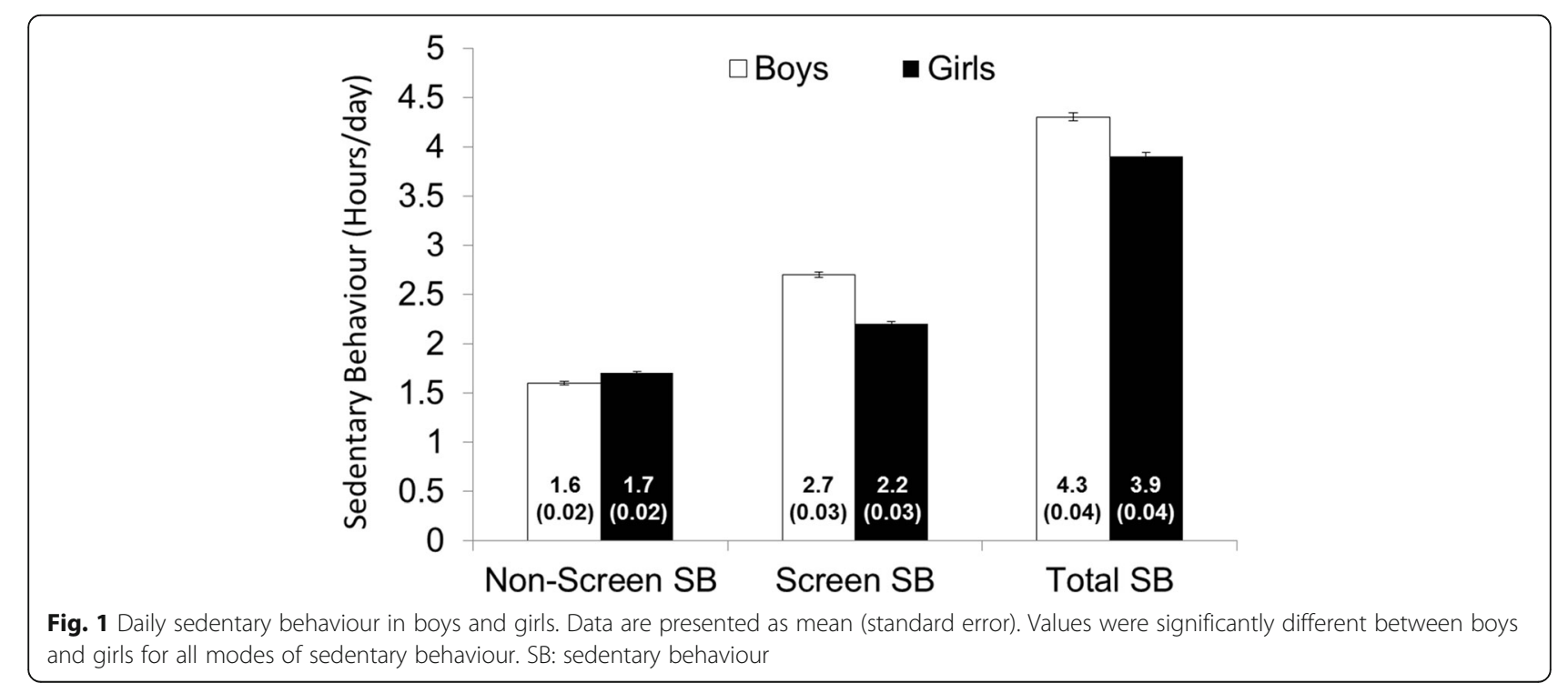


Table 4 Pearson correlation coefficients for different modes of sedentary behaviour $(n=8307)$

\begin{tabular}{|c|c|c|c|c|c|}
\hline & TV time & $\begin{array}{l}\text { Computer/video } \\
\text { game time }\end{array}$ & Total screen time & Total non-screen time & $\begin{array}{l}\text { Total sedentary } \\
\text { behaviour }\end{array}$ \\
\hline TV time & 1 & & & & \\
\hline Computer/video game time & 0.40 & 1 & & & \\
\hline Total screen time & 0.82 & 0.85 & 1 & & \\
\hline Total non-screen time & 0.15 & 0.17 & 0.19 & 1 & \\
\hline Total sedentary behaviour & 0.71 & 0.74 & 0.86 & 0.66 & 1 \\
\hline
\end{tabular}

All $p<0.05$

associated with non-screen SB in girls and the group as a whole, but not in boys when examined separately.

\section{Correlates in fully adjusted model CAPL domain scores}

In the fully adjusted model, Physical Competence and Motivation and Confidence were negatively associated with all modes of SB in the sample as a whole, which was also generally true when examining boys and girls separately (Tables 5-9). Motivation and Confidence was the strongest correlate of all screen-based modes of SB (standardized $\beta$ 's: -0.274 to -0.083 , all $p<0.05)$. Knowledge and Understanding was negatively associated with all screen-based modes of SB (standardized $\beta$ 's: -0.039 to -0.032, all $p<0.05$ ); however, it was positively associated with non-screen SB (standardized $\beta$ : 0.098, $p<0.05$ ), and there was no significant association observed for total $\mathrm{SB}$ (standardized $\beta$ : 0.020, $p>0.05$ ).

\section{Individual CAPL components}

Correlates were similar among all modes of screen-based SB, although there were important differences when comparing screen and non-screen SB. The self-reported maximum amount of time that participants felt children should spend in front of a screen each day was positively associated with all modes of SB in the full sample (standardized $\beta$ 's: 0.112 to 0.393 , all $p<0.05$ ). Log-transformed plank score and PACER score were negatively associated with all screen-based modes of SB, while CAMSA score was negatively associated with all forms of SB other than TV viewing (all $p<0.05$ ). Associations were generally similar when examining boys and girls separately, although in girls the CAMSA score was not independently associated with any mode of $\mathrm{SB}$, and PACER was independently associated only with total SB. Gender and self-reported PA were positively associated with non-screen SB (indicating higher levels for girls), and negatively associated with all modes of screen-based SB (all $p<0.05)$. Age was positively associated with all modes of SB other than TV viewing $(p=0.051)$. Grip strength and sit and reach were not associated with any mode of SB in the fully adjusted model (all $p>0.05$ ).

\section{Discussion}

The purpose of the present study was to identify whether aspects of PL were associated with key modes of SB among children participating in the RBC-CAPL Learn to Play study. Our results demonstrate significant correlations between common modes of SB and important aspects of PL. Further, our results suggest that the relationship between $\mathrm{PL}$ and $\mathrm{SB}$ differ based on the mode of SB being examined. We observed that Physical Competence and Motivation and Confidence were negatively associated with all modes of SB in the group as a whole, with the largest $\beta$ coefficients observed for Motivation and Confidence. In the fully adjusted models, a 1-point increase in Motivation and Confidence was associated with 13 minutes/day less total SB, while a similar increase in Physical Competence was associated with 3 minutes/day less total SB. These results suggest that although all CAPL domains are related to important modes of SB, targeting Motivation and Confidence may offer the best means of intervening on SB (or vice versa).

Similar findings were observed for individual CAPL components. Plank and PACER scores were negatively associated with screen-based $\mathrm{SB}$ and total SB, but not non-screen SB. Self-reported PA was positively associated with non-screen $\mathrm{SB}$, and negatively associated with all other modes of SB. The fully adjusted model of individual CAPL components accounted for $23 \%$ of the variance in screen-based SB, but just 3\% of the variance in non-screen SB. Among screen-based SB, CAPL components also accounted for a greater proportion of the variance in computer and video game use (23\%), when compared to TV viewing (11\%). These results suggest that PL is more strongly negatively associated with screen-based modes of SB, and especially computer and video game use, rather than non-screen $\mathrm{SB}$.

These results are supported by other recent findings that have also shown contrasting correlates for screen-based and non-screen SBs. For example, a recent systematic review by Carson et al. [4] concluded that reading time was not consistently associated with any physical health indicator, whereas screen-based SBs were associated with unfavourable measures of body composition, 


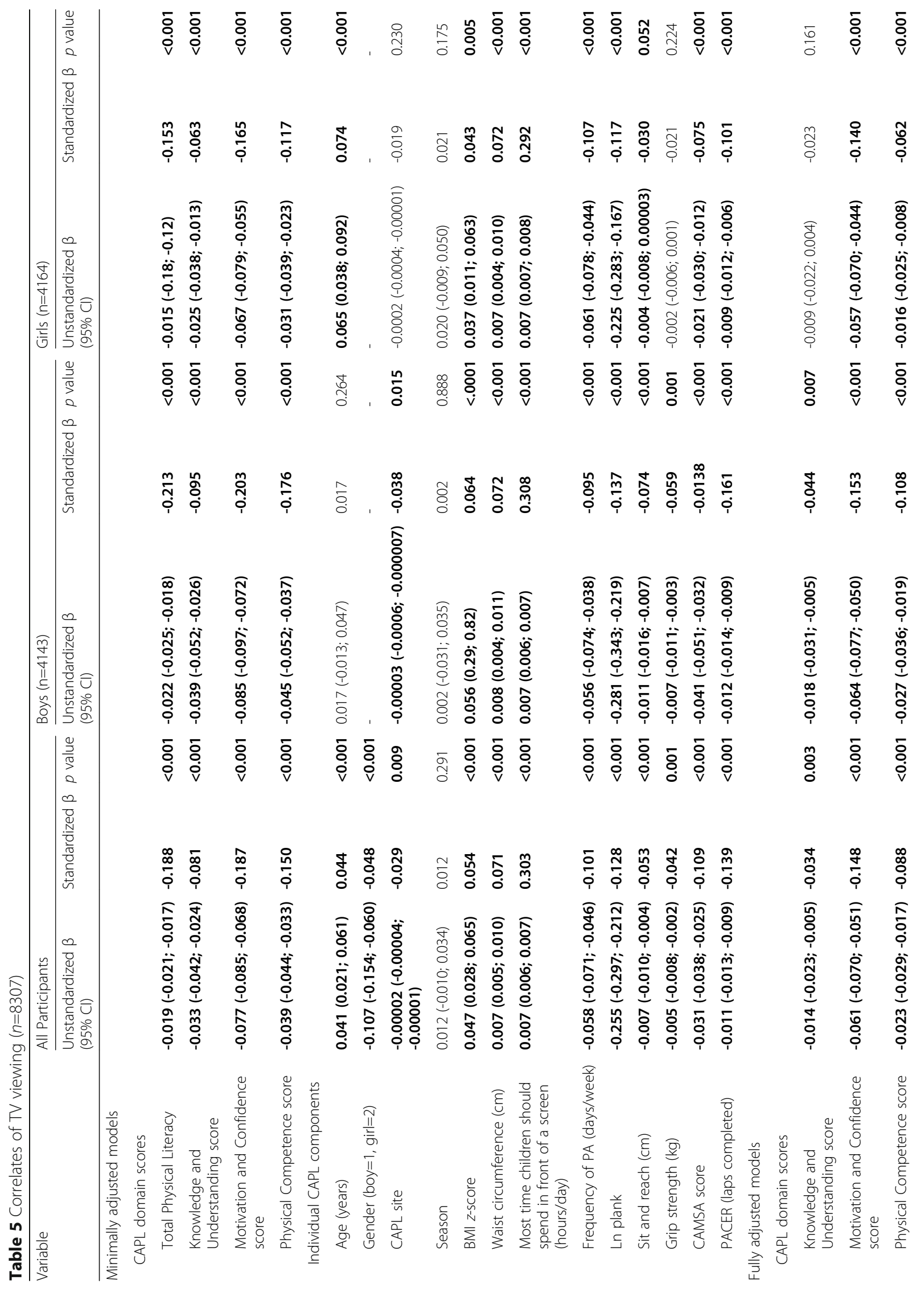




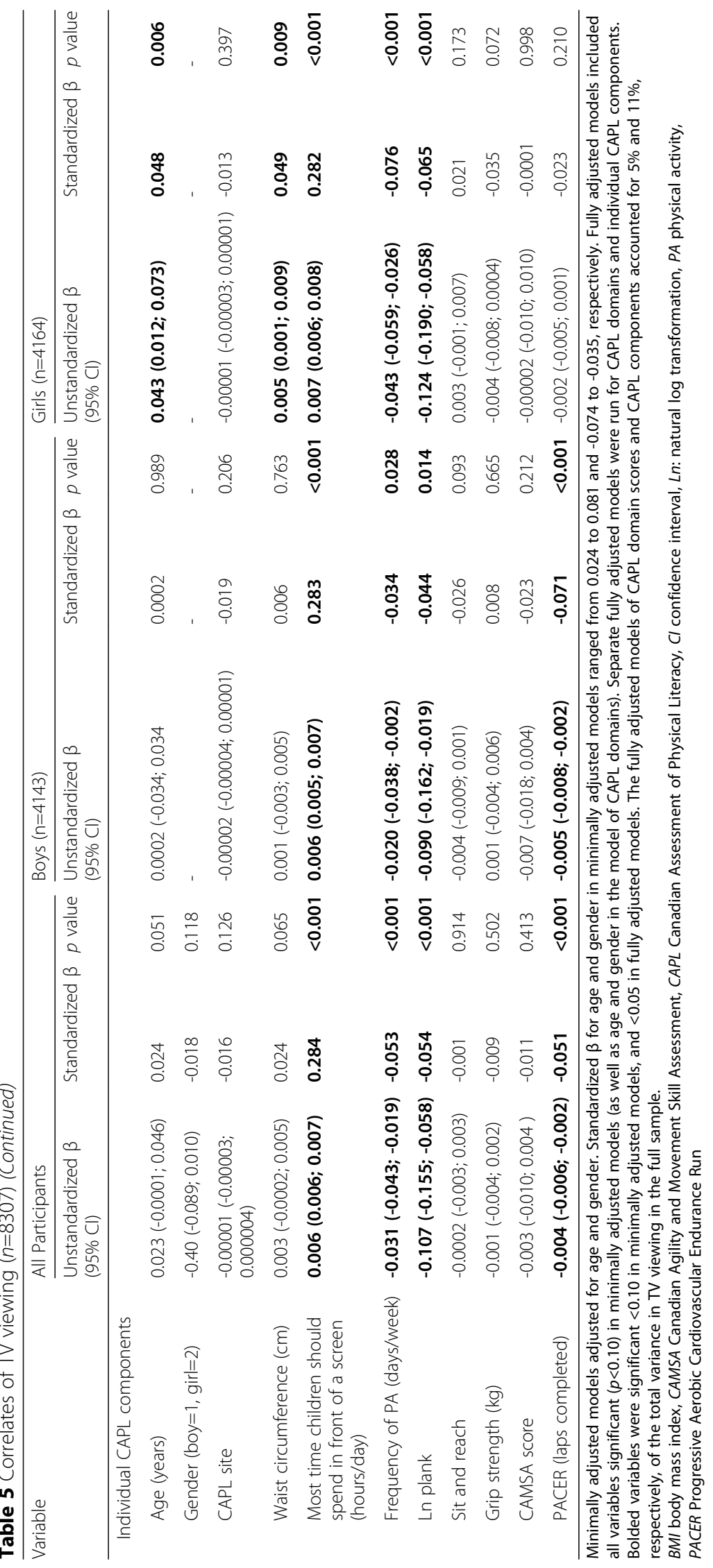




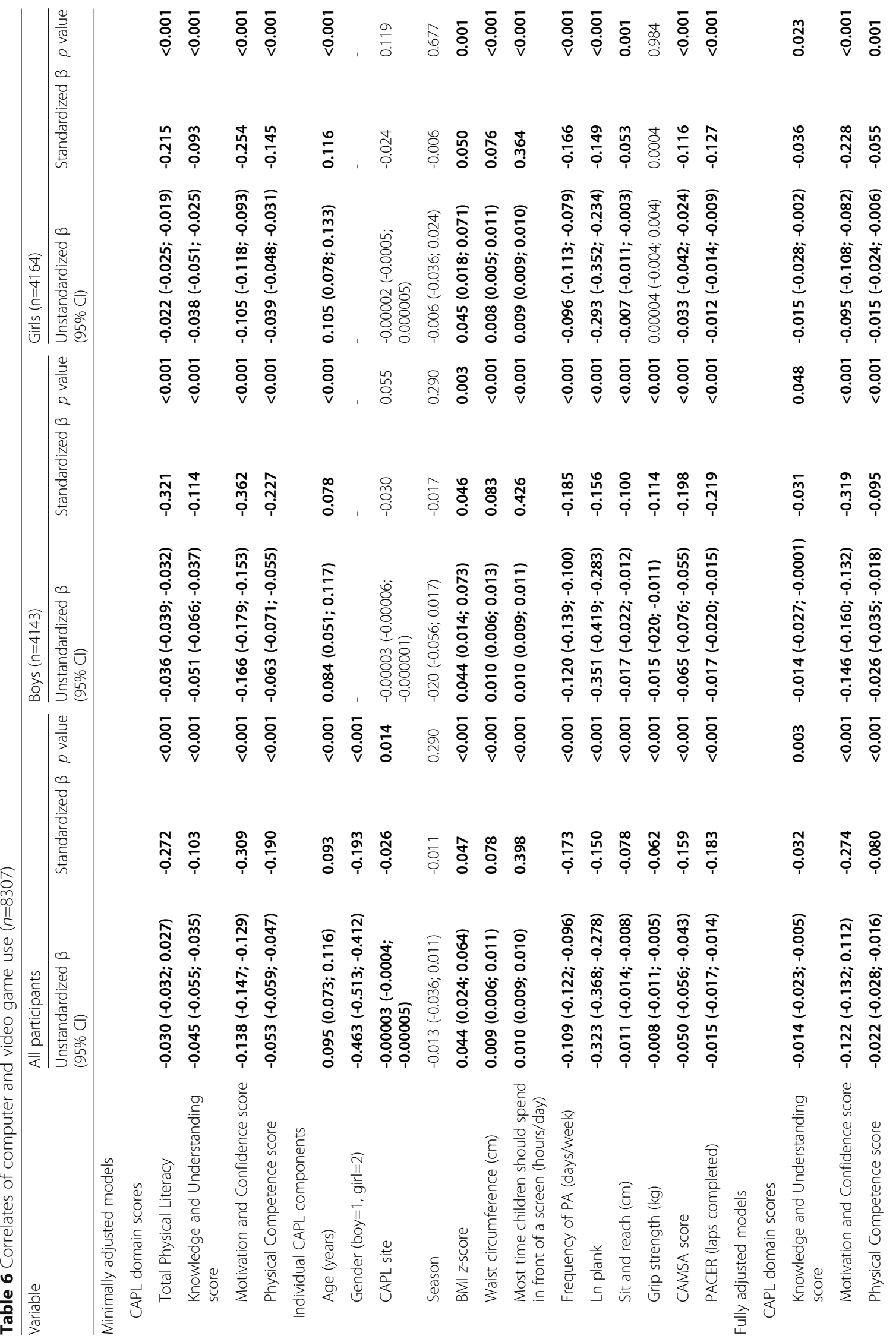




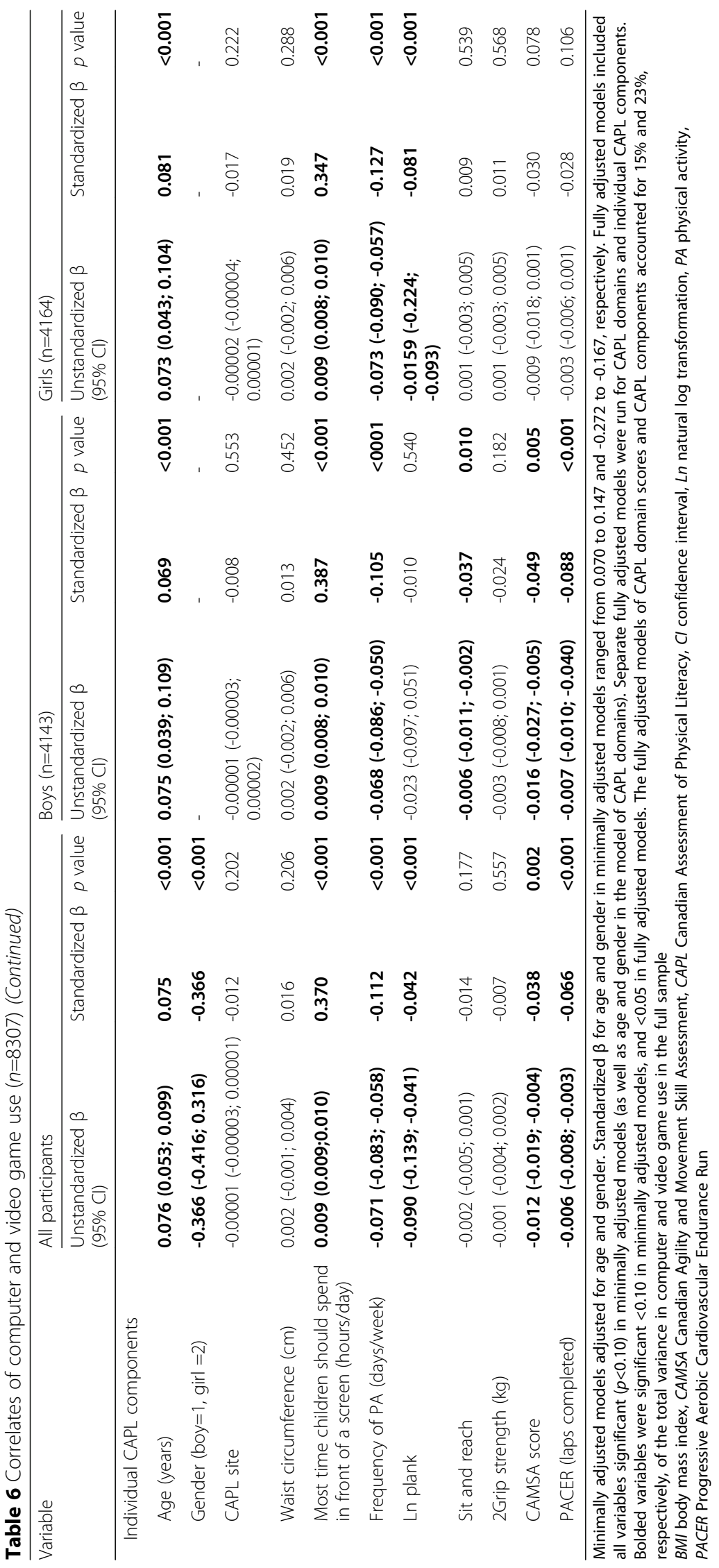




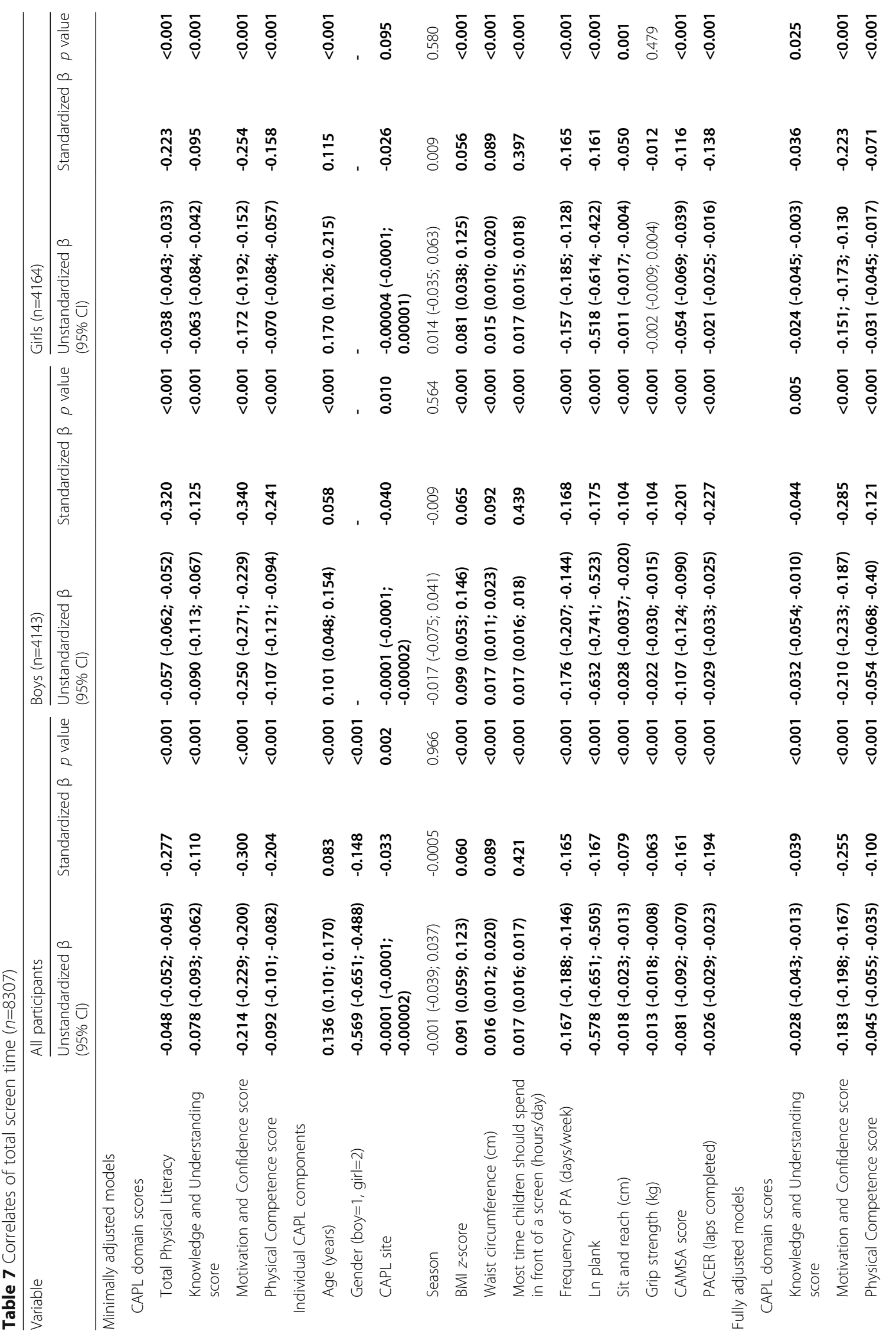




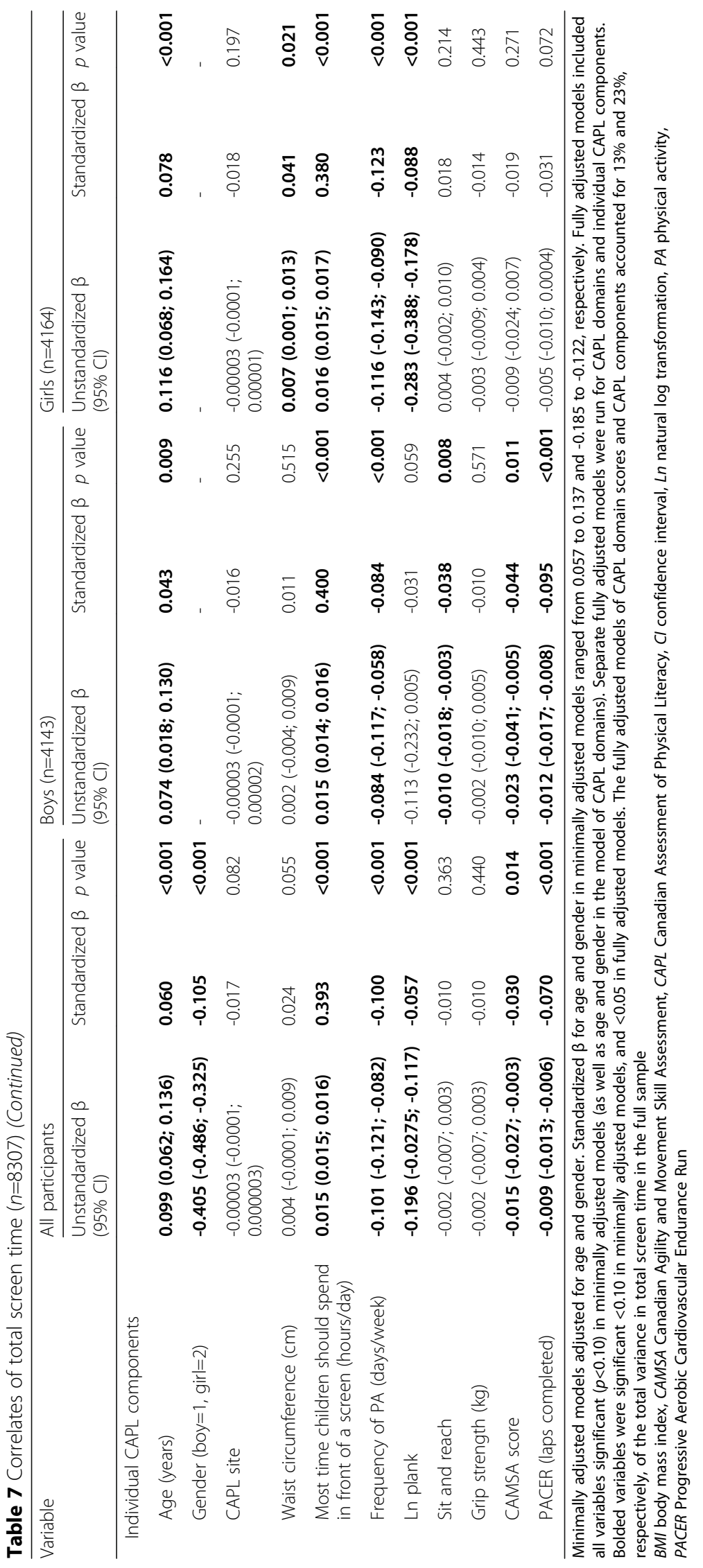




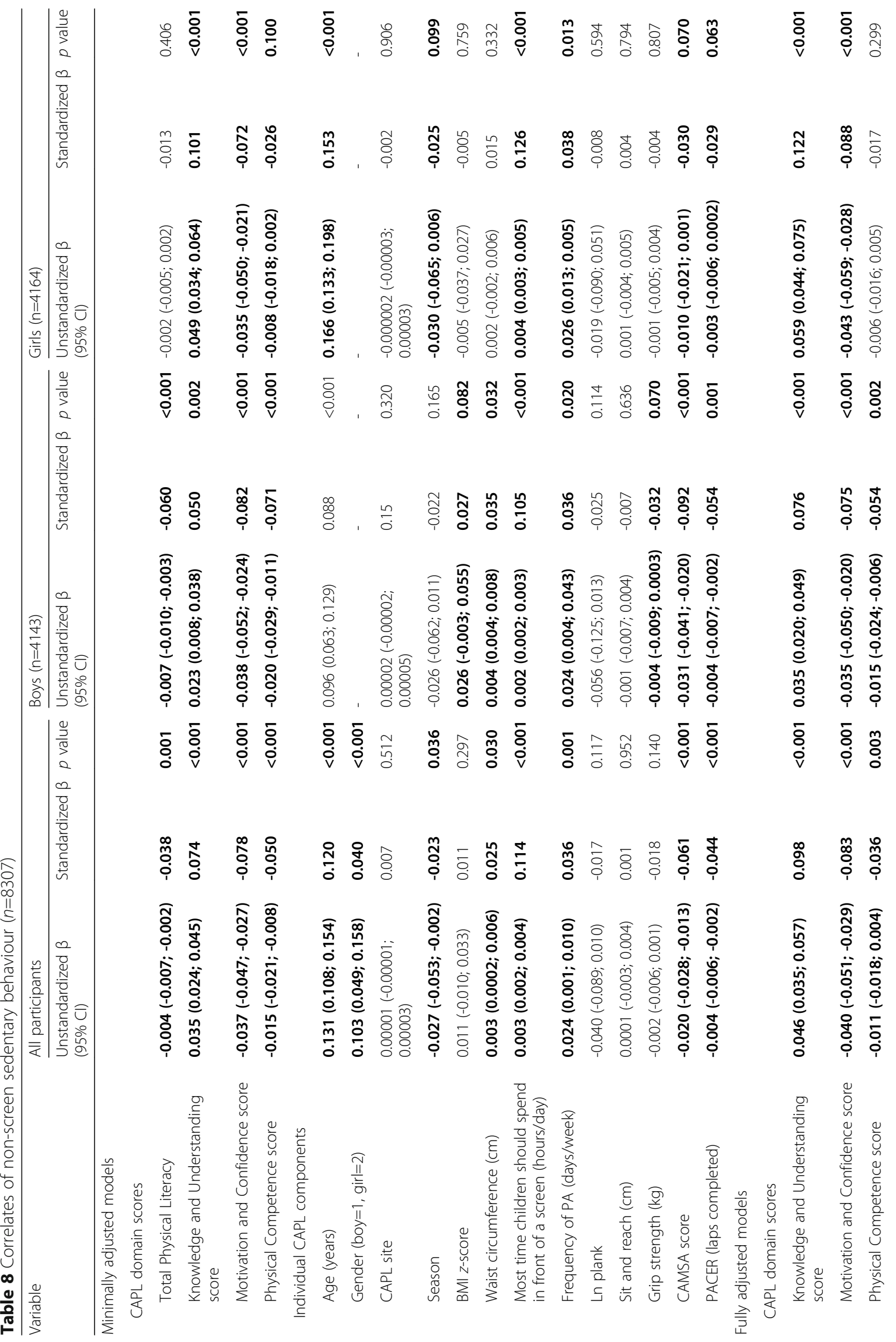




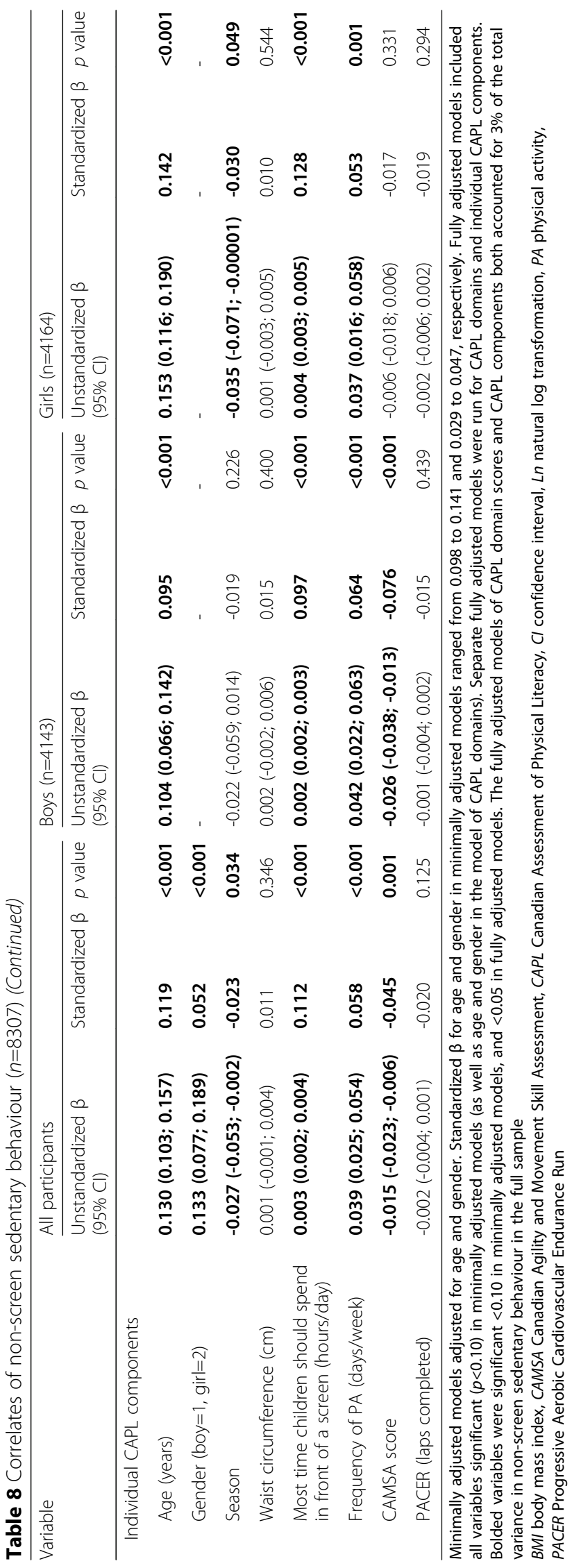




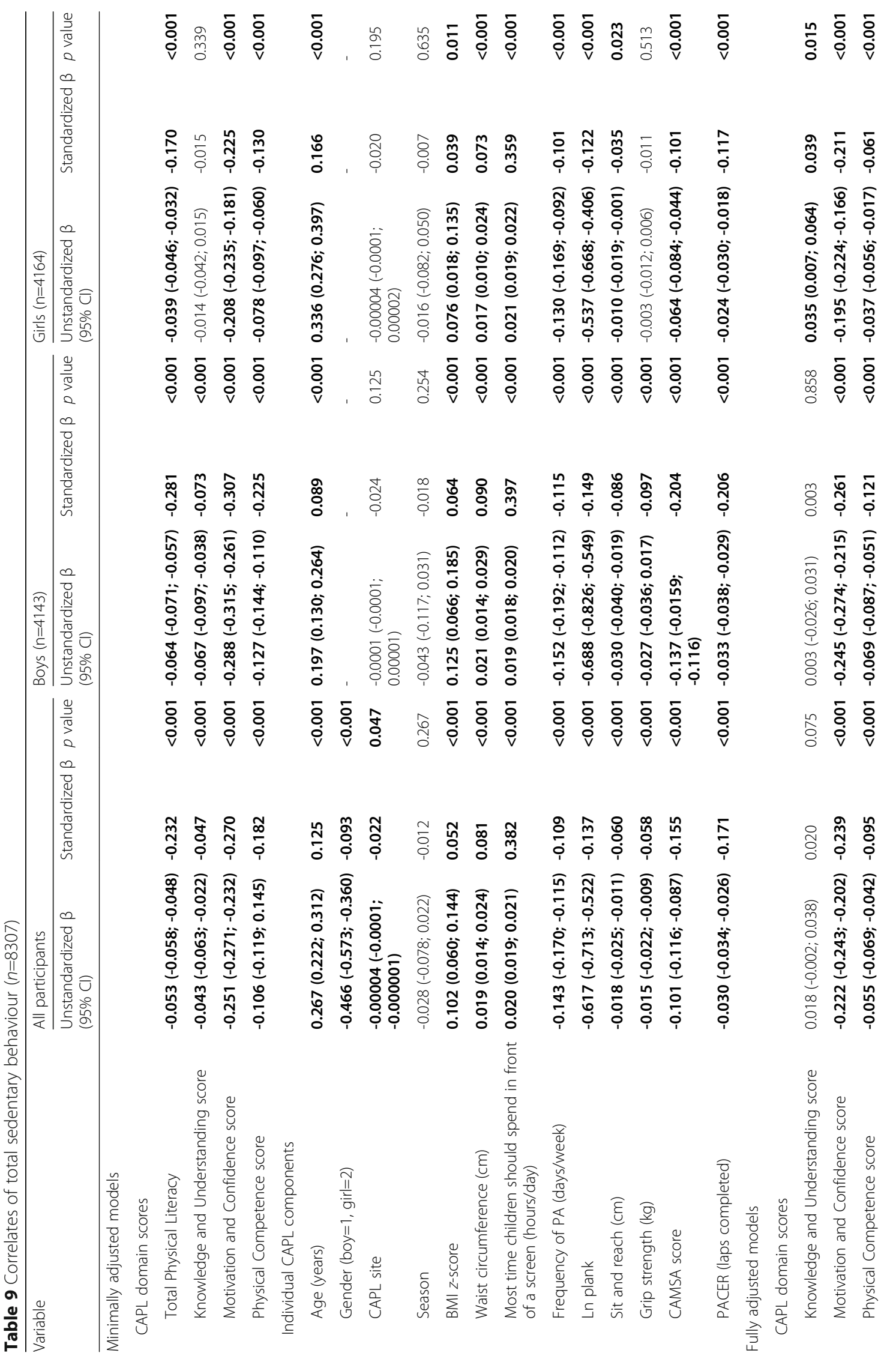




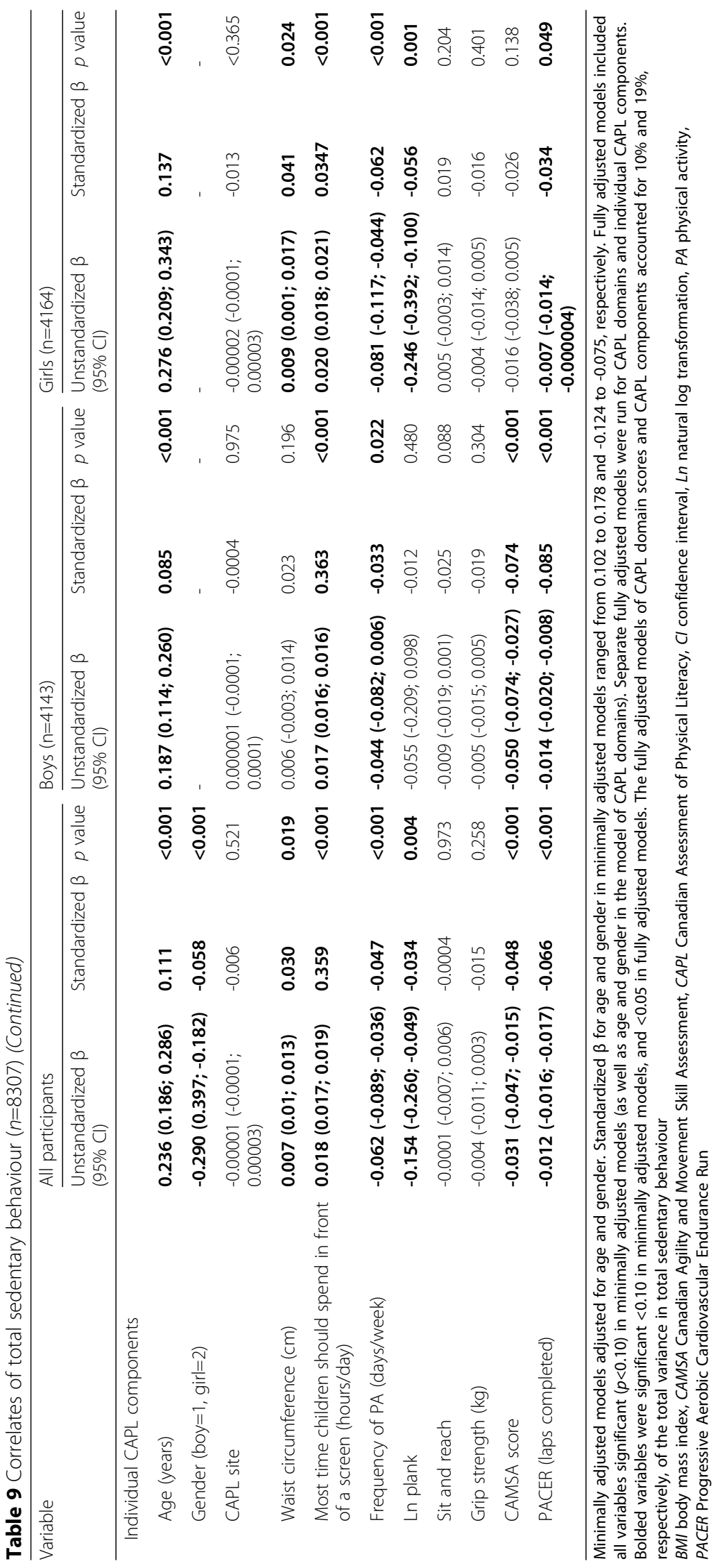


aerobic and musculoskeletal fitness, cardiometabolic health, prosocial behaviour, and self-esteem. In contrast to screen-based SBs, our results demonstrate that there may be differential effects associated with non-screen SB.

Knowledge and Understanding and self-reported PA were both negatively associated with screen-based modes of SB, but positively associated with non-screen $\mathrm{SB}$. The examples provided for non-screen $\mathrm{SB}$ in the self-report questionnaire were reading, homework, talking to friends, and drawing. It is perhaps not surprising that non-screen SB was positively associated with the Knowledge and Understanding domain of PL, given that reading and homework could expose children to important concepts related to PL, physical activity, and health. The magnitude of this association, however, was small; a 1-unit higher Knowledge and Understanding score was associated with a 3 minute/day increase in non-screen SB.

The positive association between non-screen-based SB and the frequency of PA is more difficult to explain, although not unprecedented. For example, in 10,900 American adults, Dunton et al. [29] found that PA was positively associated with time spent reading. It is possible that this relationship is mediated through increased PL-related Knowledge and Understanding. The current study did not assess parental socio-economic status, which is positively associated with reading achievement $[30,31]$. It is therefore plausible that non-screen SBs could serve as a proxy for socio-economic status, which is also associated with childhood PA [32]. Previous work has shown that certain health-related behaviours tend to cluster together [33], which could contribute to the associations observed in the present study as well. As with Knowledge and Understanding, the clinical significance of this relationship is questionable; an extra day/week of PA was associated with less than 1 minute/day higher non-screen SB. Nonetheless, these findings suggest that time spent in non-screen SB may not adversely affect time spent in PA, and is likely preferable to time spent in other forms of SB. Future research should further investigate the association between non-screen-based $\mathrm{SB}$ and PA in this age group, as well as comparing the health impacts of different combinations of screen and non-screen SB.

The most consistent positive correlate of all modes of $\mathrm{SB}$ was a question asking children to select the maximum amount of time a child should spend using screens each day. Children who indicated a higher acceptable level for daily screen time had higher levels for each mode of SB, in both the group as a whole and in boys and girls separately. Previous research indicates that children who have rules related to screen time tend to watch less TV $[34,35]$. Not surprisingly, children whose parents accumulate large amounts of screen time are more likely to get more screen time themselves $[34,35]$. It is plausible that children who believe 2-4 hours/day is an acceptable level of screen time, live in households with fewer rules and/or less positive role modelling related to SB. However, the magnitude of the association for this correlate was small. Based on the fully adjusted model, children who selected the lowest acceptable amount of screen time (30 minutes/day) would be expected to have just 3 minutes/day less screen time than those who indicated the highest value (4 hours/day). Although this association is novel, our results indicate that simply educating children on acceptable levels of screen time may not result in a large reduction in daily SB.

Similar to previous research, our findings suggest that SB increases with age [36]. In the fully adjusted models, we saw that each 1-year increase in age was associated with a 14-minute increase in total SB, with smaller increases observed for individual modes of SB. Future interventions should therefore explore ways to minimize age-related increases in SB.

When examining both genders combined, waist circumference was associated with all modes of SB in the minimally adjusted model, but only with total SB in the fully adjusted model. Among girls (but not boys), waist circumference was associated with TV viewing and total screen time. Waist circumference was not associated with computer/video game use or non-screen SB in either gender. This is in contrast with previous research, which has generally found consistent associations between screen time (especially TV viewing) and markers of body composition in both genders $[4,11]$. There has, however, been evidence for gender-based differences in the associations between waist circumference and SB modalities in this age group. A previous study by our group [37] found that waist circumference was independently associated with TV viewing in girls only, and with computer time in boys only. It is unclear why waist circumference was not associated with any mode of SB in boys in the present study. It may be because previous research did not adjust for direct measures of cardiorespiratory and musculoskeletal fitness, which were more consistently associated with all modes of SB in the present analysis. This is supported by a recent factor analysis that concluded that body composition does not contribute significantly to the total CAPL score [38].

In the present analysis, season of data collection was independently associated with non-screen SB, indicating less non-screen SB as the year progressed from winter through fall. However, the magnitude of this relationship was small - a change in season was associated with just a 1.6 minute/day reduction in non-screen SB. Further, there was no significant relationship observed between season of data collection and any screen-based mode of SB. These findings are supported by previous research, which has generally found little or no relationship 
between season and SB in other samples of children and youth [39-41]. This is in contrast to PA, which has been shown to decrease during periods of cold and/or wet weather $[42,43]$. These findings suggest that self-reported SB, especially screen-based SB, is relatively consistent throughout the year among this age group.

In the present study, $54 \%$ of children reported meeting the Canadian screen time guidelines of $\leq 2$ hours/day of recreational screen time. This is similar to the prevalence of 10 year-old Canadian children who met these guidelines in the International Study of Childhood Obesity, Lifestyle and the Environment (ISCOLE) [11]. We observed no clear patterns with respect to regional differences in total SB or meeting the screen guidelines, and individual CAPL sites were not associated with any specific mode of SB in the fully adjusted model. In line with previous research [11, 37], boys accumulated higher levels of TV, computer time, total screen time, and total $\mathrm{SB}$, while girls accumulated more non-screen-SB; as well, girls were more likely (61\% vs $48 \%$ ) to report meeting Canada's screen time guidelines. These findings illustrate a generally healthier pattern of SB among girls compared to boys. These results highlight important gender differences in the pattern of SB, and suggest that SB interventions and public health strategies should be tailored depending on the age, gender, interests, and baseline habits of participants.

The present study employed linear regression models to investigate correlates of SB. Now that potential correlates have been identified, other techniques (e.g., structural equation modelling) may be useful to further investigate relationships between correlates and SB in future studies. This may be especially useful with respect to the Knowledge and Understanding and Motivation and Confidence domains, which rely on self-reported information, and would lend themselves to this approach.

\section{Strengths and limitations}

The present study obtained a large sample size $(>8,000$ participants), collected from 11 sites across Canada, with roughly equal numbers of boys and girls. However, the number of participants approached for participation was not recorded. Although there were some statistically significant differences between those with missing data when compared to those with complete data, the magnitude of the differences was small and unlikely to be of clinical significance. To date this study is the largest examination of $\mathrm{PL}$ in this age group, used validated measurement tools, and included directly measured fitness, body composition, and motor performance. However, all modes of SB were self-reported, as was the frequency of PA participation, and this type of reporting can increase error and bias [44] when compared to objective measures. The current study investigated both screen and non-screen modes of SB, although screen use focused exclusively on TV, computer, and video game use. We therefore were unable to investigate the relationship between PL and other types of screen use, including tablets and smartphones. In addition, a cross-sectional design was employed, and therefore this study cannot be used to infer causality. Further, although we noted several independent correlates of SB, the magnitude of individual associations was small in the fully adjusted models. Finally, the present study did not assess socio-demographic variables such as income, parental education, or family structure, and therefore could not evaluate whether these variables would influence the relationship between PL and SB.

\section{Conclusions}

Our findings show that key modes of SB are associated with total PL, as well as the Motivation and Confidence, Knowledge and Understanding, and Physical Competence domains. Motivation and Confidence demonstrated the strongest association with screen-based modes of SB, while Knowledge and Understanding showed positive associations with non-screen $\mathrm{SB}$, and negative associations with screen-based SB.

In the fully adjusted model, the self-reported amount of time that participants felt that children should spend in front of a screen each day was positively associated with all modes of SB, while PACER and log-transformed plank scores were negatively associated with screen-based SB. Self-reported PA was negatively associated with screen-based modes of SB, and positively associated with non-screen SB. These results highlight the important differences between screen and non-screen SB, and suggest that public health interventions should continue to target screen-based SBs, given their deleterious associations with important aspects of PL. Interventions attempting to reduce screen-based SB may benefit from increasing children's Motivation and Confidence, given the consistent and independent associations observed in the present analysis. Promotion of non-screen SB may have small benefits for some aspects of PL (Knowledge and Understanding, and self-reported PA), but negative changes for others (total PL, Motivation and Competence, and Physical Competence). Finally, interventions should be tailored to participant gender and age, which are associated with multiple modes of SB in this age group.

\section{Abbreviations}

BMI: body mass index; CAMSA: Canadian Agility and Movement Skill Assessment; CAPL: Canadian Assessment of Physical Literacy;

CSAPPA: Children's Self-Perception of Adequacy in and Predilection for Physical Activity; Ln: natural log transformation; MET: metabolic equivalent;

PA: physical activity; PACER: Progressive Aerobic Cardiovascular Endurance Run; PL: physical literacy; RBC-CAPL: Royal Bank of Canada-Canadian Assessment of Physical Literacy; SB: sedentary behaviour 


\section{Acknowledgements}

We would like to acknowledge all the research assistants who helped gather data for this study.

\section{Funding}

This study was funded by the Royal Bank of Canada, the Public Health Agency of Canada, and Mitacs, and was delivered in partnership with ParticipACTION. Publication charges for this article have been funded by the RBC Learn to Play project and the Public Health Agency of Canada, delivered in partnership with ParticipACTION.

\section{Availability of data and materials}

The datasets supporting the conclusions of this article are available upon reasonable request to Dr. Mark Tremblay (mtremblay@cheo.on.ca).

\section{About this supplement}

This article has been published as part of BMC Public Health Volume 18 Supplement 2, 2018: Canadian Assessment of Physical Literacy. The full contents of the supplement are available online at https://bmcpublichealth. biomedcentral.com/articles/supplements/volume-18-supplement-2.

\section{Authors' contributions}

MST and PEL were responsible for the RBC-CAPL Learn to Play study design. TJS, DJM, and JLC developed the research questions and objectives for this study. TJS, DJM, and JB led the data analysis and synthesis of results. TJS wrote the manuscript. DJM, JLC, PEL, JB, KB, BB, MJG, NH, AMK, BL, LJM, DS, MRS, SJW, and MST were responsible for reviewing and revising the manuscript for important intellectual content. All authors read and approved the final manuscript.

\section{Ethics approval and consent to participate}

Ethics approval was obtained from: Antigonish - St. Francis University Research Ethics Board and the Strait Regional School Board; Calgary - Mount Royal University Human Research Ethics Board; Charlottetown - University of Prince Edward Island Research Ethics Board and the Prince Edward Island Public Schools Branch Research Ethics Board; Halifax - Dalhousie University Research and Ethics Board and the Halifax Regional School Board; Lethbridge - University of Lethbridge Human Subject Research Committee; North Bay Nipissing University Research Ethics Board, Near North District School Board, Nipissing Parry Sound Catholic District School Board, and Conseil Scolaire Catholique Franco-Nord; Ottawa - Children's Hospital of Eastern Ontario Research Ethics Board, University of Ottawa Research Ethics Board, OttawaCarleton District School Board, Ottawa Catholic School Board, Conseil des écoles catholiques du Centre-Est, Conseil des écoles publiques de l'Est de I'Ontario, Upper Canada District School Board, Durham District School Board, University of Illinois at Urbana-Champaign; Trois-Rivières - Université du Québec à Trois-Rivières Research Ethics Board; Victoria - Camosun College Research Ethics Board and the Greater Victoria School District: Windsor University of Windsor Research Ethics Board and the Windsor Essex Catholic District School Board; Winnipeg - The University of Winnipeg University Human Research Ethics Board (UHREB), River East Transcona School Division, and St. James-Assiniboia School Division. Written informed consent was obtained from parents or legal guardians, and participating children also provided verbal assent.

\section{Consent for publication}

Not applicable.

\section{Competing interests}

The authors declare that they have no competing interests.

\section{Publisher's Note}

Springer Nature remains neutral with regard to jurisdictional claims in published maps and institutional affiliations.

\section{Author details}

'Department of Applied Human Sciences, University of Prince Edward Island, 550 University Avenue, Charlottetown, PE C1A 4P3, Canada. ${ }^{2}$ Department of Kinesiology and Physical Education, University of Lethbridge, Lethbridge, $A B$ T1K 3M4, Canada. ${ }^{3}$ Healthy Active Living and Obesity (HALO) Research Group, Children's Hospital of Eastern Ontario Research Institute, Ottawa, ON
K1H 8L1, Canada. ${ }^{4}$ School of Physical and Health Education, Nipissing University, North Bay, ON P1B 8L7, Canada. ${ }^{5}$ Department of Kinesiology and Applied Health, University of Winnipeg, Winnipeg, MB R3B 2E9, Canada. ${ }^{6}$ Department of Human Kinetics, St. Francis Xavier University, Antigonish, NS B2G 0W5, Canada. 'School of Kinesiology and Health Studies, Queen's University, Kingston, ON K7L 3N6, Canada. ${ }^{8}$ Faculty of Health, Community and Education, Mount Royal University, Calgary, AB T3E 6K6, Canada. ${ }^{9}$ School of Health and Human Performance, Dalhousie University, Halifax, NS B3H 4R2, Canada. ${ }^{10}$ Department of Kinesiology, University of Windsor, Windsor, ON N9B 3P4, Canada.

Published: 2 October 2018

\section{References}

1. Tremblay MS, Aubert S, Barnes JD, Saunders TJ, Carson V, Latimer-Cheung $A E$, et al. Sedentary Behavior Research Network (SBRN) - Terminology Consensus Project process and outcome. Int J Behav Nutr Phys Act. 2017;14:75.

2. Saunders T, Vallance JK. Screen time and health indicators among children and youth: current evidence, limitations and future directions. Appl Health Econ Health Policy. 2017;15:323-31.

3. Saunders TJ, Chaput J-P, Tremblay MS. Sedentary behaviour as an emerging risk factor for cardiometabolic diseases in children and youth. Can J Diabetes. 2014:38:53-61.

4. Carson V, Hunter S, Kuzik N, Gray C, Poitras V, Chaput J-P, et al. Systematic review of the relationships between sedentary behaviour and health indicators in school-aged children and youth: an update. Appl Physiol Nutr Metab. 2016:41(6 Suppl 3):S240-65.

5. LeBlanc AG, Spence JC, Carson V, Connor Gorber S, Dillman C, Janssen I, et al. Systematic review of sedentary behaviour and health indicators in the early years (aged 0-4 years). Appl Physiol Nutr Metab. 2012;37:753-72.

6. Tremblay M, LeBlanc AG, Kho M, Saunders TJ, Larouche R, Colley R, et al. Systematic review of sedentary behaviour and health indicators in schoolaged children and youth. Int J Behav Nutr Phys Act. 2011;8:98.

7. Physical Literacy Consensus Statement. ParticipACTION. 2015. https://www. participaction.com/en-ca/thought-leadership/research/physical-literacyconsensus-statement. Accessed 17 May 2017.

8. Tremblay MS. Major initiatives related to childhood obesity and physical inactivity in Canada: the year in review. Can J Public Health. 2007:98:457-9.

9. Longmuir PE, Boyer C, Lloyd M, Yang Y, Boiarskaia E, Zhu W, et al. The Canadian Assessment of Physical Literacy: methods for children in grades 4 to 6 (8 to 12 years). BMC Public Health. 2015;15:767.

10. Bernaards CM, Hildebrandt VH, Hendriksen IJM. Correlates of sedentary time in different age groups: results from a large cross sectional Dutch survey. BMC Public Health. 2016;16:1121.

11. LeBlanc AG, Katzmarzyk PT, Barreira TV, Broyles ST, Chaput J-P, Church TS, et al. Correlates of total sedentary time and screen time in 9-11 year-old children around the world: the International Study of Childhood Obesity, Lifestyle and the Environment. PLOS ONE. 2015;10:e0129622.

12. LeBlanc AG, Broyles ST, Chaput J-P, Leduc G, Boyer C, Borghese MM, et al. Correlates of objectively measured sedentary time and self-reported screen time in Canadian children. Int J Behav Nutr Phys Act. 2015;12:38.

13. Muthuri SK, Wachira L-JM, Leblanc AG, Francis CE, Sampson M, Onywera VO, et al. Temporal trends and correlates of physical activity, sedentary behaviour, and physical fitness among school-aged Children in sub-Saharan Africa: a systematic review. Int J Environ Res Public Health. 2014;11:3327-59.

14. Salmon J, Tremblay MS, Marshall SJ, Hume C. Health risks, correlates, and interventions to reduce sedentary behavior in young people. Am J Prev Med. 2011;41:197-206.

15. van Sluijs EMF, Page A, Ommundsen Y, Griffin SJ. Behavioural and social correlates of sedentary time in young people. Br J Sports Med. 2010;44:747-55.

16. Healthy Active Living and Obesity Research Group. Canadian Assessment of Physical Literacy (CAPL). 2014. https://www.capl-ecsfp.ca/. Accessed 5 Jul 2017.

17. Tremblay MS, Longmuir PE, Barnes JD, Belanger K, Anderson K, Bruner BM, et al. Physical literacy levels of Canadian children aged 8-12 years: Descriptive and normative results from the RBC Learn to Play CAPL Project. BMC Public Health. 2018;18(Suppl 2).

18. Hay J. Adequacy in and predilection for physical activity in children. Clin J Sports Med. 1992;2:192-201. 
19. Colley RC, Barnes JD, Leblanc AG, Borghese M, Boyer C, Tremblay MS. Validity of the SC-StepMX pedometer during treadmill walking and running Appl Physiol Nutr Metab Physiol. 2013;38:520-4.

20. Boyer C, Tremblay M, Saunders TJ, McFarlane A, Borghese M, Lloyd M, et al. Feasibility, validity and reliability of the plank isometric hold as a field-based assessment of torso muscular endurance for children 8-12 years of age. Pediatr Exerc Sci. 2013;25:407-22.

21. Longmuir PE, Boyer C, Lloyd M, Borghese MM, Knight E, Saunders TJ, et al. Canadian Agility and Movement Skill Assessment (CAMSA): validity, objectivity, and reliability evidence for children 8-12 years of age. J Sport Health Sci. 2017;6:231-40.

22. Morrow JR, Martin SB, Jackson AW. Reliability and Validity of the FITNESSGRAM ${ }^{\oplus}$. Res Q Exerc Sport. 2010;81:S24-30.

23. Saunders TJ, Gray CE, Borghese MM, McFarlane A, Mbonu A, Ferraro ZM, et al. Validity of SC-StepRx pedometer-derived moderate and vigorous physical activity during treadmill walking and running in a heterogeneous sample of children and youth. BMC Public Health. 2014;14:519.

24. Tudor-Locke C, McClain JJ, Hart TL, Sisson SB, Washington TL. Expected values for pedometer-determined physical activity in youth. Res Q Exerc Sport. 2009;80:164-74.

25. Tudor-Locke C, Burkett L, Reis JP, Ainsworth BE, Macera CA, Wilson DK. How many days of pedometer monitoring predict weekly physical activity in adults? Prev Med. 2005:40:293-8.

26. Canadian Society for Exercise Physiology. CSEP PATH: Physical activity training for life. Ottawa: Canadian Society for Exercise Physiology; 2013.

27. WHO Multicentre Growth Reference Study Group. WHO child growth standards: length/height-for-age, weight-for-age, weight-for-length, weightfor-height and body mass index-for-age: methods and development. 2006. http://www.who.int/childgrowth/en/. Accessed 6 June 2017.

28. Garcia AW, Broda MAN, Frenn M, Coviak C, Pender NJ, Ronis DL. Gender and developmental differences in exercise beliefs among youth and prediction of their exercise behavior. J Sch Health. 1995:65:213-9.

29. Dunton GF, Berrigan D, Ballard-Barbash R, Graubard B, Atienza AA. Joint associations of physical activity and sedentary behaviors with body mass index: results from a time use survey of US adults. Int J Obes. 2009;33:1427-36.

30. Chatterji M. Reading achievement gaps, correlates, and moderators of early reading achievement: evidence from the Early Childhood Longitudinal Study (ECLS) kindergarten to first grade sample. J Educ Psychol. 2006:98:489.

31. van Bergen E, van Zuijen T, Bishop D, de Jong PF. Why are home literacy environment and children's reading skills associated? What parental skills reveal. Read Res Q. 2017;52:147-60.

32. Gustafson SL, Rhodes RE. Parental correlates of physical activity in children and early adolescents. Sports Med. 2006;36:79-97.

33. Woodruff SJ, Hanning RM. Associations between diet quality and physical activity measures among a southern Ontario regional sample of grade 6 students. Appl Physiol Nutr Metab. 2010;35:826-33.

34. Salmon J, Timperio A, Telford A, Carver A, Crawford D. Association of family environment with children's television viewing and with low level of physical activity. Obes Res. 2005;13:1939-51.

35. Thompson JL, Sebire SJ, Kesten JM, Zahra J, Edwards M, Solomon-Moore E, et al. How parents perceive screen viewing in their 5-6 year old child within the context of their own screen viewing time: a mixed-methods study. BMC Public Health. 2017;17:471

36. Bucksch J, Sigmundova D, Hamrik Z, Troped PJ, Melkevik O, Ahluwalia N, et al. International trends in adolescent screen-time behaviors from 2002 to 2010. J Adolesc Health. 2016;58:417-25.

37. Saunders TJ, Tremblay MS, Mathieu M-Ë, Henderson M, O'Loughlin J, Tremblay A, et al. Associations of sedentary behavior, sedentary bouts and breaks in sedentary time with cardiometabolic risk in children with a family history of obesity. PLOS ONE. 2013;8:e79143.

38. Gunnell KE, Longmuir PE, Barnes JD, Belanger K, Tremblay MS. Refining the Canadian Assessment of Physical Literacy based on theory and factor analyses. BMC Public Health. 2018;18(Suppl 2). https://doi.org/10.1186/ s12889-018-5899-2

39. Fisher A, Reilly JJ, Montgomery C, Kelly LA, Williamson A, Jackson DM, et al. Seasonality in physical activity and sedentary behavior in young children. Pediatr Exerc Sci. 2005;17:31-40

40. Biddle SJH, Gorely T, Marshall SJ, Cameron N. The prevalence of sedentary behavior and physical activity in leisure time: a study of Scottish adolescents using ecological momentary assessment. Prev Med. 2009:48:151-5.
41. Devís-Devís J, Peiró-Velert C, Beltrán-Carrillo VJ, Tomás JM. Screen media time usage of 12-16 year-old Spanish school adolescents: effects of personal and socioeconomic factors, season and type of day. J Adolesc. 2009:32:213-31.

42. Tucker $P$, Gilliland J. The effect of season and weather on physical activity: a systematic review. Public Health. 2007;121:909-22.

43. Bélanger M, Gray-Donald K, O'Loughlin J, Paradis G, Hanley J. Influence of weather conditions and season on physical activity in adolescents. Ann Epidemiol. 2009;19:180-6.

44. Saunders TJ, Prince SA, Tremblay MS. Clustering of children's activity behaviour: the use of self-report versus direct measures. Int J Behav Nutr Phys Act. 2011:8:48. author reply 49

\section{Ready to submit your research? Choose BMC and benefit from:}

- fast, convenient online submission

- thorough peer review by experienced researchers in your field

- rapid publication on acceptance

- support for research data, including large and complex data types

- gold Open Access which fosters wider collaboration and increased citations

- maximum visibility for your research: over $100 \mathrm{M}$ website views per year

At BMC, research is always in progress.

Learn more biomedcentral.com/submissions 